\title{
Analysis of the Urban Management Practices and Sustainable Development in the Local Municipalities in Jordan: Case Study - Salt City
}

\author{
Ahmad Khlaifat ${ }^{1}$, Hala Abu Taleb ${ }^{2}$, Zeyad Makhamreh ${ }^{1} \&$ Deya $_{\text {Qtiashat }}{ }^{1}$ \\ ${ }^{1}$ Department of Geography, Faculty of Arts, University of Jordan, Amman, Jordan \\ ${ }^{2}$ Department of English Studies, Faculty of Foreign Languages, University of Jordan, Amman, Jordan \\ Correspondence: Zeyad Makhamreh, Department of Geography, Faculty of Arts, University of Jordan, Amman, \\ Jordan. E-mail: z.makhamreh@ju.edu.jo
}

$\begin{aligned} & \text { Received: January 6, } 2018 \quad \text { Accepted: March 14, } 2018 \quad \text { Online Published: March 18, } 2018 \\ & \text { doi:10.5539/mas.v12n4p109 }\end{aligned}$ URL: https://doi.org/10.5539/mas.v12n4p109

\begin{abstract}
The urbanization processes and the accelerated growth in the Arab countries, during the last five decades, have resulted in negative social impact represented in the high rates of unemployment and poverty. This was accompanied with problems related to the provision of infrastructure and social facilities, inadequate housing for low-income persons and other environmental problems. Therefore, there is a need to apply and activate the role of decentralization processes to manage the cities under emerging modern urban services and activities, in order to identify policies and cope with innovative plans that suit for sustainable urban development. Incorporations of local people and decision makers in improving social, economic and environmental conditions, and participation of local people in decision making can lead to find the appropriate solution that can promote sustainable urban processes, and facilities the implementation of the local communities' activities. Consequently, this will lead to improve the urban services in appropriate quality and economic visibility and sustain social consistency and environmental resources in the cities. In order to achieve a sustainable development practices in the municipalities, it is recommended to focus on local community resources, increase financial income, develop local human resources proficiency, and finally empower the local people authority and decision -making process, which can be achieved by the application of decentralization governance system.
\end{abstract}

Keywords: urban management, sustainable development, salt municipality, Jordan

\section{Introduction}

Since the twentieth century, the world has been influenced by accelerated changes in the political, economic and administrative conditions. It witnessed the emergence of new intractable problems, especially in the third world countries, at the national level in the economic, social and environmental sectors, this was accompanied with increasing population growth, uncontrolled spreading of urban settlement and the widespread poverty and unemployment (KAAU, 2006). Nowadays, Jordan facing a shift towards respecting the characteristics of communities, as a result of consequences of both globalization and modernization. However, the centralization system is no longer successful in taking the role of local state that was applied since the 1960 s, following the failure of many national plans and programs that adopted this approach (Atiqa, 2011). Therefore, appropriate solutions are need to be created to solve those issues which can be achieved by introduction of the decentralization governance system in the country.

In this regard, achieving public participation through decentralized management is considered as an important factor for activation of public participation in achieving sustainable urban development. Taking into consideration, the weak role of current central government and the municipalities, in meeting the needs of community. For these reasons, many countries have moved towards implementing the decentralization system, in order to empower the local communities and achieving balance between the dimensions of sustainable development and urban physical development (Toukhi, 2006). In Jordan, the committees of decentralized management in the governorate are formed through the direct election by community's members, and the head of decentralization is chosen by the election among the member themselves. In this context, application of decentralization in Jordan starts in 2015 aims to apply bottom-up community-based principal decision, in order 
to meet the needs of local communities by activating the public participation in addressing the basic needs of population (MOPD, 2017)

There are recognized failure of the local municipalities in providing the basic services in a quality suiting the modern life pattern and keeping the sustainable urban development. Therefore, the objective of this study is to assess the current services and examine the potential role of municipalities in decentralization process in Salt city in the context of sustainable urban development. Its importance is generated by the increasing attention of researchers and decision- makers in the decentralized management, in light of the phenomenon of globalization, and the shifting of world countries towards applying the decentralized management.

\section{Progress achieved in Salt Municipalities}

The study followed the analytical descriptive approach and a field survey that carried out in 2017 in order to identify the role of decentralization process regarding the sustainable urban development and the physical development, beside that a detailed survey on a related previous studies has been collected and analyzed. Below is a brief description of the role of greater Salt municipality and the main projects and activities that was implemented in the city.

\subsection{The Role of the Greater Salt Municipality}

The municipality of Greater Salt plays an important role in the development and provision of services to local citizens. Local councils represent a form of administrative decentralization that are characterized by financial and administrative independence and have legal legitimacy, and are inherited from the local community. The local bodies are of vital importance directly in their relationship with the local citizens because they are found to serve them and satisfy their various desires in order to achieve a comfortable life quality, and happiness for the local citizens. Therefore, the role of the municipality is to achieve the two main objectives: Translate the community from a consumer service stage to a production state and to provide basic services for the citizens in their local community in cooperation with representatives of the central authority. The process of local administration is to organize the efforts of the community and develop its capabilities in management and maximizing its achievements for integrated sustainable urban development (GSM, 2016).

The Salt municipality works to provide services, and organize the different uses of land organization, planning and construction of various infrastructure through its specialized institutions at the local level. The importance of municipality's as a regional organization with its jurisdiction is one of the most important factors in achieving sustainable urban development, through optimization of the land tenure type assignment according to the law of land organization. Also, it is responsible for the development and decisions making through the municipality court, improving the economic and social systems which is the main components of sustainable urban development. It is worth to mention that, the local development process in Jordan is linked with the urban and rural geographical units aiming to identify the needs and problems of the local infrastructure services. The role of the municipality in the local development is through providing basic services, and creating different projects in the fields of tourism, agriculture, industry to bringing the gab in the social and economic status between the populations.

\subsection{Projects Established in Salt City}

The Municipality has endeavored to emphasize the importance of public participation of individuals and institutions in the sustainable urban development through the investing and adoption of a number of projects. Here a list of the most important of them:

\section{Heritage Award Project}

This project involves improvement of the urban environment of the historic downtown area and the preservation of heritage buildings. It includes the city center and emphasis on the concept of cooperation and participation between the municipality and the members of the community by supporting the individual and collective efforts of citizens in the process of restoration of buildings. This project has helped to create and bring about the sustainable urban and economic development of the city by encouraging citizens to participate in the preservation of the city's heritage by implementations this project, positive results have been achieved which help to reach the concept of sustainable development and the main results are highlighted below. This project improves the urban environment and development of the city, restoration of old buildings that have been neglected over time, rehabilitations of some heritage symbols that constitute the core of city's history that have used for various purposes such as commercial and social functions (GSM, 2014). 


\section{Rehabilitation of the Old Landfill}

This project was established in cooperation between the National Women's Committees and the Greater Salt Municipality with support and funding obtained from the United State Agency for International Development. The purpose of this project is focused on conservation of the environment through the exploitation of the landfill site that have an overlooking sight on the Jordan Valley. It involves rehabilitation of the site to a public park serving the local communities, and activates the participation of citizens in the local and public activities in the city, encourage the investments in local tourism pattern in the region, and preserving the surrounding environment. As this project has contributed to the process of attracting investments to the city and attracting hikers and queues (ESF, 2015).

\section{Development of the Downtown Center}

The Salt city center suffers from many problems related to mismanagement and neglecting of the urban center where heritage buildings face the risk of extinction as a result of exposure to climatic and natural factors, beside that the failure to perform the necessary maintenance in addition to abandonment and non-exploitation in various functions and activities. Hence the importance of a project is to develop and promote the economic and social aspects in the city center. The project was funded and supported by JICA and in collaboration with the Greater Salt Municipality and the Eamar Salt Foundation. Project achievements are improve the access to the social and economic development of the city through activating the local and international tourism. Preserve the urban heritage of the city and highlight the architectural elements of the existing city's heritage. Expanding the participation of the local community in the tourism and commercial activities, which generate a financial and social return to the local community (ESF, 2015).

\section{Establishing an Urban Information System}

Knowledge requires gathering data and generating information in order to be ready and accessible for planners whenever they need. Local municipalities must provide an accurate information, which require creating local information bodies that have the responsibilities of gathering, analyzing and monitoring the economic, social and environmental indicators. The existence of such data set would increase the efficiency of solving the problems from the perspective of knowledge. Therefore, the municipality has sought to create this system through partnership and cooperation between the municipality and Balqa Applied University by studying the urban, economic and social characteristics of the population in the salt city. The main outcomes of this project are creating a database to study economic and social features of population according to their spatial distribution. Investigate the needs and desires of the population in terms of services and development aspects, where the projects adopted by municipality are generated as a result of a realistic and actual study. Also, study the spatial dimension of environmental problems confronting the city population, and come up with appropriate solutions (GSM, 2014).

\section{Previous Studies}

Mahran, (2001) studied the factors affecting the continuity of the urban development process in Cairo, it aiming for identifying the factors influencing the physical development, and the applicability of Geographic Information System (GIS) for achieving a balanced in physical and urban development. The study concluded that achieving physical development requires the using of modern techniques and programs such as GIS.

Goodwen, (2003) illustrated the concept of sustainable cities, the study divides the sustainable development process into five types and considered the financial availability as the basic pillar requires for sustainable urban development. Also, it demonstrates the importance of good management practices and their role in development process. As this study used the theoretical approach to understand and evaluate the urban growth, it focused on the urban expansion as one form of suburbs cities. The results clarified that urban areas and its expansion in the present time is a major challenge to decision makers. The complexity of the urban processes requires using new methodological approaches such as the descriptive approach integrated with the remote sensing techniques.

Esters, (2008), addressed the growing role of urban sprawl as a positive process in development of local communities. This poses one of the main challenges in the twenty first century, where city's population comprise over half world's population. This can be indicating negative aspects represented by the changes in population characteristics, biodiversity and restrictions of agricultural lands. The study emphasizing the importance of having harmonious cities that offers a decent life for populations and able to face challenges imposed by the accelerated urban expansion. The main recommendation is the development of knowledge and technology associated with the urban management of environmental sustainability basis.

Suribabu and Bhashkar, (2014) studied the Urban Sprawl and the land uses types which play a vital role in 
optimization of the urban management. It relies on the analytical descriptive approach in the analysis and clarified the role of technological space data, especially remote sensing data and GIS that become increasingly used in the urban studies. The factors affecting the urban expansion processes, are changes in the type of land use and organization, population density and urban expansion.

Abu Hilu, (2014) has review the important requirements that lead to the success of sustainable urban development in the absence of spatial planning policies, regional and national levels in the Palestinian territories. This study focusing on accommodation of future urbanization processes in the framework of the current development rate, and to the proposals and recommendations of the steps required to reach the integration between the desired plans and levels of development. It considered the most important basic ingredients that affect the reality and future of sustainable development in the Palestinian territories. The methodology of the work is based on application of geographical information systems, and the descriptive approach that used in the monitoring of the land evolution use.

Al-Janabi, (2014) discussed the ideas of sustainability and seek to restore the balance, and continuity of life on earth in the present, while preserving the right of future generations to meet their needs in the future. The methodology is based on the field study to determine the possibility of achieving a sustainable approach for green cities, this include the scientific analytical approach, filed survey and theoretical studies. The study clarifies the concept of sustainability, as it is not confined to the construction of the environment in the modern cities. However, it concentrates on the growing interest in the issues of planning, urban management, under the protection of the environment and reduce the use of energy. This based on use of renewable sources, and the optimal exploitation of natural resources and strengthen the economic, social and cultural rights. The study concluded that green architecture reflects the new ways and methods in interaction with the urban area.

\section{Sustainable Development Process and Decision Making}

Decentralization has been defined as a process in which power is transferred from central to local authority members that elected by the citizens. It involves distribution of administrative function between the central authority and elected local bodies that truly represents the local populations. Its own the authority to decide and act upon different issues related to the interests of these local populations, under the supervision of the central authority (Toukan, 2001).

Various definitions have addressed decentralization concept that reflects the differences in opinions of researchers and intellectuals, from the local authority' perspective, and differences in points of view. However, the ultimate goal is to achieve sustainable management in all aspects of economic, political, social and environmental developments.

Al-Zoubi (1986) defined decentralization as sharing administrative functions between the central government, and the local elected bodies and councils that perform their functions under the supervision of the government. Rabab'a (1995) considered decentralization as new governance method of the country's administrative regulation, based on sharing activities and duties between the central authorities and the elected local authorities. It gives an opportunity to draw public policies, and works efficiently on following-up and running local services and achieving the local communities' goals.

\subsection{Sustainable Urban Development}

Despite the differences in defining the sustainable development, it rationalizes the recruitment of renewable resources in a way that protect it from fading, deterioration or diminishing rights for future generation. It also contains the prudence in the utilization non-renewable resources, allowing future generation utilizes it. Sustainable development requires also the consumption of non-renewable resources at a slow rate in order to ensure gradual transition to renewable energy resources (AHDR, 2003).

Urban sustainable development is defined as providing the present needs without jeopardizing rights of future generation. It involves meeting their needs aside to improving the people's life quality, health and economic conditions without depletion of resources according to Agenda 21. In this regards sustainable development seeks to achieve a number of objectives (Idreekh, 2005). These are improving and developing the natural environment, beside activation of the public participation, formulation and review of policies and decision making related to social justice.

It highlights on finding a balance among a number of objectives at various levels. Social justice could be affected along with the development of the economic system in some areas where economy savings are available, to the detriment of other poor resource regions (Swailem, 2008). Satisfying individual's needs can affect the local requirements that negatively affect basic resources. Achieving this balance needs the provision of integrated 
management and restructuring of administrative system in order to achieve goals and priorities of the sustainable urban development (Ravetz, 1999)

The process of sustainable urban development can have conceived according to the universally agreed concept, it characterized by partnership in the scarce natural resources, between successive generations, including all types of natural resources and the surroundings environments (Alribdawi, 2010). The current generations are seeking to make the most of all natural resources, whether available or under exploration, they keep in mind providing guarantees for a fair distribution of these recourses through successive generations. The method of sustainable development includes doing an organized economic development to achieve a maximum limit of social and economic gains in the present, without depriving future generations of similar opportunities in the future. The primary objective of adopting optimal ways of sustainable urban development is the ability to reach an even and rational distribution of a level of economic welfare that can continue without shortage or prejudice to successive generations (Deeb, 2009).

Through introducing measurable indicators for socio-economic and environmental parameters, sustainable urban development state can be achieved, reach directions and solve problems, where it can also be considered as an assessment tool for sustainable urban development gains within community. It can also be adapted to follow- up conditions of development and the possibility of progress, revise impacts of development policies and stimulate participation regarding sustainable issues. Development indicators can also help in reaching basic needs to face problems, and discovering the weaknesses resulting from socio-economic and environmental relations (Al-Daghestani, 2009).

\subsection{Decentralization Process}

Atiqa, (2011) referred to the role of decentralization in achieving sustainable urban development through convergence and integration with the central system, and finding essential changes at the economic, political, social and environmental levels within local community, which in turn leads to achieve economic welfare for communities. This is accompanied with expanding and stimulating public participation in managing their requirements, developing, and decision-making process for achieving sustainable urban development.

Decentralization is characterized in the right of participation taking administrative decision, without diminishing the role of central authority in decision-making. It is based on tasks distribution and decision making between government authorities and elected bodies which represents local community. Decentralization represented in activating the role of local and regional authorities, through distributing administrative and developmental tasks. It highlights its role in taking responsibility in a way that incorporates public participation in processes of local development (Alfra, 2010).

The administrative side represented in the process of preparing, implementing and following-up local development plans needs to be addressed with professionalism, in order to ensure the success of these plans in achieving their objectives. The failure of many development plans, especially the rural one, in many countries of the third world is basically resulting from the administrative methods followed in the management of development plans during their implementation, and not because of the shortage in the natural resources themselves.

On the other hand, decentralization is the only way through which local goals are transformed into a general framework that can be used as a local development strategy, allowing public participation, and guaranteeing coherence, harmony and integration between bodies and institutions concerned in preparing and implementing local development plans (Al-Taher, 2011).

Planning process under decentralization must concentrate and care about activating public participation in preparing and implementing local development plans, in the so-called, from bottom planning method. Planning and building from bottom serves in achieving one basic principle of successful development according to (Alshaikhli, 2002).

Effective implementing of decentralization, in the sustainable urban development, works on creating development programs, in order to meet the needs and requirements of population. It allows public participation in preparing and implementing of development plans for their areas, which in turn provides national and local development plans the chances of success in achieving their goals in a balanced way that guarantees providing a decent life for all population in all areas within the county. It also contributes to achieving regional balance, and reducing economic, regional and social disparities, which based basically on distributing decision-making authority between the different authority's bodies. 


\subsection{State of Urban Development in Salt City}

Urban physical development is concerning with the civilized appearance, and reflect the real image of the economic, political, social and regulatory conditions in the community's. The idea of urban physical development appeared in several international and global conferences where definitions of sustainable physical development were introduced. Its content was to improve quality of life within the framework of resources and energy management without posing challenges for future generations, and without depleting these resources. Therefore, it is important to achieve the balancing between resources use and management, in addition to the financial resources which constitute a prominent role in all current and future decisions regarding physical development principles (Deeb, 2009).

State of the urban development in the third world countries including Jordan has been affected by increasing the pressure on the available services, scarcity of available resources and accelerated population growth. The deteriorations of urban services, fast spreading of sprawl and urban slums accompanied with failure of transport system. Beside the administrative and financial problems that facing the central administrative system that focuses on capital city, through provide services and maintenance, collect taxes and marginalize other areas. This lead to emergence of unsustainable urban environments, and therefore, implementing and improving strategic plans concerning physical development are necessities in order to improve the quality of services and life in the local communities. From the perspectives of sustainable development, an affordable effort should be done for achieving sustainability in the development process, by paying attention to the management and natural resources and developing human resources for urban areas. (Hildebrand, 1999).

The indicators of urban development of the salt city that discussed in this section were population growth, expansion of the houses number in the urban part, and presence of educational institutions. Salt city is one of the Jordanian cities of the region and its proximity to the capital Amman. It is the main center of Balqa Governorate, which contributed to highlighting its historical role. The percentage of the population growth of the city of Salt was increased between 1979 and 2015 by $23 \%$. This influence the various aspects of economic, commercial, service and commercial activities as well as realization of urban city plan. It is worth to mention that the city combines the originality and the modernity of housing structure, where there are archaeological and historical monuments and ancient Islamic landmarks. Existence of the modern urban plans and through the services and roads and paved streets and spacious buildings and buildings, which has become an attractive factor for housing, especially in addition to the existence of many companies and financial institutions and banks. The expansion in the number of houses in the city and surrounding the city of Salt, which is part of the overall development witnessed in the city where the total residential units in the city of Salt in 2015 is distributed throughout the city center. The existence of educational institutions in the city, it includes the oldest educational schools in the country, as well as the University of Applied Balqa and the College of Salt.

\subsection{Decentralization Role in Sustainable Development in Al-Salt City}

Nowadays, many world countries including Jordan are seeking to implement decentralization process in their administrative system, especially, with the pressure they face from the international organizations, which imposes having a highly skilled and qualified staff, aiming for optimizing the resource management and development of local communities. Various studies have concentrated on implementing decentralization process especially, in the management of sustainable physical development (ESCWA, 2001), where decentralization considered to be a reliable system that in order to manage the city, improve local community and have the ability to make decisions and implement it in high efficiency.

Decentralization works on the direct contact with the government authorities and emphasizes on implementing a mechanism of dialogue and partnership between local community and centralized decision makers. Most important goal of sustainability can be achieved by activating the role of public and local participation, through interdisciplinary team working on local requirements and manage resources. Jordan start to establish a special management associated with urbanization, which represents one pillar of physical planning by developing strategies, policies, and physical plans to reach sustainability through implementing the decentralization process in the governorates.

In this regards, habitat Agenda has introduced a strategy that guarantees achieving urban sustainability, and it revolves around the following points: Enable public participation in developing plans and making decisions regarding priorities of local community. Introduce modern technological programs, to facilitate participation in the sustainable urban development. Provide experienced people that capable of implementing and making decisions in field of physical development. Stimulate the role of public participation between government and private sectors, in order to improve interdisciplinary decision making. 
Many governorates and cities in the world suffer from the unplanned physical growth that affects natural resources that including agricultural lands, which causing traffic congestion and high level of pollution, and therefore, it consists an obstacle to sustainable urban development. In this context, implementing and following-up the proper decentralization system could result in striking a balance between social, political, economic and environmental goals. This system, can help in the conservation of natural resources without wasting them, the provision of sustainable urban services and the activation of public participation for improving the local development activities.

Through studying realities of sustainable urban development and physical development, the study found that, despite activating the role of decentralization role, it suffers from many problems that appears due to the following reasons: Weakness of local community experience, and its inability to define its requirements. Absence of sound projects that meets the needs of the local community for developments process. Lack of comprehensive awareness for the concept of development and disaggregated sense of local collaborations and weak role of nongovernmental institutions and private sector.

In Jordan, the decentralization system will become the primary base of the administration authority in the country governorates, where these bodies enjoy legal personality with financial and administrative autonomy as they represent the public participation in conducting the domestic affairs within the local community. It is an integrated process of the administrative, political, economic, social and cultural sustainable development at the local and regional level. The decentralization council is the mandate holder in determining and approving different types of development projects in the governorates.

The decentralization council in Al-Salt city consists from different committees in order to support local community management process, beside the role of participation. The local community committees aim to examine, improve and develop the basis of services provided to the citizens in the city and it is consisted from five committees. The first committee is the financial, economic, development and tourism committee. It seeks to identify the needs of the city and local community for different types of services projects. Provide suggestions for project investment that would be of benefit within local community. The decentralization council looks for providing economic services and initiatives to develop the economic system within the local community, as a consequence, achieving sustainable economic and touristic development in the city.

The second committees are the agriculture, water, energy and mineral wealth. Among its responsibilities are to investigate and evaluate the agricultural and water resources in the governorates, in addition to submit proposals regarding its sustainable development of resources in the city. In addition to Pursuit all activities that would develop and enhance the agriculture sector, and encourage it to achieve inner-city sustainable agriculture development. Contribute to the protection of agricultural land, best utilization of water resources, and other mineral resources.

The third committees are the health, environment and public work, it performs the following functions: Study the health services provided to the citizens, and promote the needed plans in order to improve health sector. Engage the local community in the environment protection, through rising awareness and volunteer works. The forth committees are the education committee which seeks to develop the education sector and introduce modern technological education system in the different studying stages, and develop cultural facilities and promote dissemination of education and culture in the city. The fifth committees are the local community committee, it seeks to follow-up all committees in the city and the services that provided to the community and citizens at the same time. It also follow-up the workflow of these committees in all activities that conducted by the municipality.

\section{Recommendations}

The main recommendations of this paper is to focus on local community by providing and training the human resources on the governance and decentralization system and empower them for decision-making process in the framework of public interest of communities. Strengthen the role of non-governmental institutions and private sector in development of the local community. Develop and activate awareness programs specialized in the sustainable development by promote the sense of belonging to the local communities and activate the role of public participation on the local level. Identify the sustainable urban plans and strategies at the local level of cities, in order to provide the social, urban, environmental and economic requirements for improving the living standards of population. Develop adequate plans to control the physical expansion in favor of agricultural lands, and provide adequate related urban services that needed to sustain communities. Increasing the integration and coherence between urban and physical development through the coordination between government authorities and the private sector. 


\section{References}

Abu Ali, N. (2010). Sustainable development in the traditional architecture in the Kingdom of Saudi Arabia, Master, Umm Al-Qura University.

Abu Hilu, M. (2014). The requirements of sustainable urban development in the absence of regional schemes in the Palestinian territories. Journal of a generation of human and social sciences, 2, 201-218.

AHDR. (2003). Sustainable development in the Arab World (3rd ed).

Al-Daghestani, I. S. (2009). The management of sustainable development in the urban environment of the city of Baghdad.

Alfra, M. A. (2010). Strategies for achieving sustainable urban planning in the Gaza Strip using geographic information systems (GIS), Master, Islamic University of Gaza.

Alribdawi, Q. (2010). Population growth and urban development in the Sultanate of Oman, The Journal of the University of Damascus.

Alshaikhli, A. (2002). The relationship between the central government and the local administration.

Al-Taher, A. (2011). The mechanisms for activating the role of municipalities in local development management in Algeria, Master.

Alzo'ubi, K. (1986). The formation of local councils and their impact on the adequacy of city Management. Cairo, Atlas.

Atiqa, K. (2011). Administrative decentralization in the Maghreb countries, Master Thesis.

Deeb, R. Y. (2009). Sustainable urban development strategy in the semi-urban areas, University of Damascus.

ESCWA, (2001). Sustainable Urban Development-a Regional Perspective on Good Urban Governance- United Nations- New York.

ESF (Emaar Salt Foundation). (2015). The reconstruction of the salt and the development publications of the city center.

Esters, R. (2008). Toward Sustainable Development: From Theory to practice, University of Pennsylvania USA.

Goodwin, N. R. (2003). Five Kinds of Capital: Useful Concepts for Sustainable development. Global Development and Environment Institute.

GSM (Greater Salt municipality). (2014). Greater Salt municipality publications.

GSM (Greater Salt municipality). (2016). Greater Salt municipality publications.

Hildebrand, F. (1999). Designing the city; towards a more Sustainable Urban Form. First publishing, E and Nspon.

Idreekh, M. O. H. (2005). Sustainable and integrated planning strategies, land and transportation use in the city of Nablus, a master's paper non-published, Najah National University.

Janabi, N (2015). The Green City as Style for Conserving Resources and Protecting the Environment from Pollution. Iraqi Journal of Architecture, 30(1-2).

KAAU. (2006). Sustainable development in the Arab world between reality and hopefully, King Abdul Aziz University, Jeddah, Kingdom of Saudi Arabia.

Mahran, A. (2001). The factors affecting the continuity of the urban development process in Cairo, Egypt.

MOPD (Ministry of Political Development). (2017). The decentralization law, the ministry publications, Amman Jordan.

Rabab'a, F. (1995). The role of central authorities and the elected local authorities in development.

Ravetz. (1999). City Region toward 2020 - Integrated Planning for a Sustainable Environment- TCPA - London.

Suribabu, C. R., \& Bhaskar, J. (2014). Evaluation of Urban Growth Using Remote Sensing and GIS Tools Case Study on Thanjavur City, Tamil Nadu, India.

Swailem, S. I. I. (2008). Strategies for the sustainability of the traditional commercial street. Master thesis, Najah National University, Palestine.

Toukan, T. (2001). Report on the decentralization and local governance in Palestine. Annual reports 22. Ramalla. 
Toukhi, S. (2006). Decentralization and the entrance to the empowerment and local sustainable development.

\section{Copyrights}

Copyright for this article is retained by the author(s), with first publication rights granted to the journal.

This is an open-access article distributed under the terms and conditions of the Creative Commons Attribution license (http://creativecommons.org/licenses/by/4.0/). 